\title{
La historieta como vehículo de conocimiento en riesgos naturales. Algues vertes: l'bistoire interdite
}

\author{
Comics as a Medium of Knorwledge in \\ Natural Risks. Algues vertes: 1'histoire interdite
}

\author{
Laura Caraballo
}

Université Clermont-Auvergne

Laura Caraballo es historiadora del arte especializada en historieta latinoamericana, particularmente en la obra del dibujante Alberto Breccia y la historieta contemporánea argentina. Ha trabajado como docente, investigadora y curadora en Francia y Argentina. Actualmente enseña en la Universidad Bordeaux Montaigne, en la escuela de diseño ELISAVA Barcelona y en la Université Clermont Auvergne. En esta institución desarrolla un proyecto de investigación postdoctoral, bajo la dirección de la profesora Viviane Alary, sobre la función de la comunicación visual (específicamente, la historieta) en la reducción de la vulnerabilidad de poblaciones particularmente expuestas a riesgos y catástrofes naturales.

Fecha de recepción: 6 de noviembre de 2021

Fecha de aceptación definitiva: 9 de diciembre de 2021 


\section{Resumen}

Algues vertes: l'bistoire interdite (Delcourt, Francia) nos permitirá establecer una mirada que concibe el lenguaje de este medio como idóneo para sintetizar los contenidos en el marco de la pedagogía y la divulgación científica. La historieta es a menudo concebida como un lenguaje narrativo simplificador y esquematizador. Contrariamente, como veremos en el caso de Algues vertes..., el potencial y el alcance de la historieta se definen por su complejidad. Posee la capacidad de convertir los datos en un objeto de placer de lectura, así como en un estímulo para la reflexión, permitiendo allanar ciertas dificultades de apropiación por parte del público, específicamente aquel expuesto a riesgos naturales concretos. Estas características se expresan ampliamente en los nuevos géneros y usos de la historieta contemporánea: reportaje periodístico, documental, de investigación o medioambiental, entre otros. A partir de una ardua investigación periodística sobre las mareas verdes en la región de Bretaña y el peligro que comportan, la periodista Inès Van Léraud se asocia al dibujante Pierre Hove y la colorista Mathilda para poner en imágenes y secuencias una exuberante masa de información y conocimiento de diferentes tipos (estadísticas, opiniones, testimonios, explicitación de operaciones mediáticas y lobbys, etc.) en relación a este daño ambiental. Nuestro análisis busca rastrear aquellas operaciones iconotextuales y secuenciales que vehiculizan conocimiento y concienciación. Cabe decir que prestamos una atención particular en el aspecto visual, como, por ejemplo, las elecciones cromáticas, formales y los diferentes modos de representación y de puesta en página que cohabitan en esta obra.

Palabras clave: cómic periodístico, operaciones discursivas, riesgo ambiental, transmisión de conocimiento 


\begin{abstract}
Algues vertes: l'bistoire interdite (Delcourt, France) will allow us to take a look beyond seeing this language only as a means to synthesize contents in pedagogy and scientific popularization. Comics are often reduced to a simplifying and schematizing narrative language. On the contrary, as we will see in the case of Algues vertes..., the potential and scope of comics are defined by its complexity. It has the ability to turn data into an object of leisure reading, as well as an instance of reflection, allowing to overcome certain difficulties of appropriation by the public, specifically those exposed to specific natural risks. These characteristics are widely expressed in the new genres and uses of contemporary comics: journalistic reporting, documentaries, research, ecology, environment, among others. Starting from an important journalistic investigation on the green tides in the Brittany region of France and their danger, journalist Inès Van Léraud associates with cartoonist Pierre Hove and colorist Mathilda to put into images and sequences an exuberant mass of information and knowledge of different types (statistics, opinions, testimonies, explicitness of media operations and lobbies, etc.), in relation to this environmental scourge. Our analysis seeks to trace those iconotextual and sequential operations that convey knowledge and awareness. That is to say, we pay particular attention to the visual aspect, such as the chromatic and formal choices and the different modes of representation and page layout that coexist in this work.
\end{abstract}

Keywords: discourse operations, environmental risk, journalistic comics, transfer of knowledge.

\title{
Cita bibliográfica
}

Caraballo, L. «La historieta como vehículo de conocimiento en riesgos naturales. Algues vertes: l'histoire interdite», en CuCo, Cuadernos de cómic, n.o 17 (2021), pp. 109125. 


\section{Introducción}

Esta investigación se enmarca en el Proyecto postdoctoral Les risques naturels au prisme de la bande dessinée de la Université Clermont-Auvergne. Nuestro corpus se compone de historietas contemporáneas que tratan sobre riesgos y catástrofes naturales. Buscamos poner de manifiesto el interés de la historieta en la transmisión de conocimiento y la concienciación para la reducción de la vulnerabilidad en poblaciones particularmente expuestas a riesgos naturales. Trabajamos sobre un amplio corpus que al momento cuenta con más de cien entradas y que nos permitirá desmenuzar los elementos propios del dispositivo, para luego establecer una serie de alineamientos que se traduzcan en recomendaciones específicas. Estas estarán destinadas a científicos que lleven a cabo proyectos de divulgación, prevención, concienciación o subsanación de riesgos naturales. Nos apoyamos, asimismo, en la colaboración con científicos de diferentes disciplinas que utilizan el dibujo y la narración visual como medio para transmitir conocimiento en función de la prevención de riesgos.

¿Cómo se transmite conocimiento a través de la secuencia iconotextual? ¿Qué ventajas puede tener la historieta en la transmisión y la divulgación? ¿Cómo se enuncia a través de la imagen y qué se elige contar? El análisis de Algues vertes: l'bistoire interdite nos orienta hacia algunas respuestas, específicamente en el género periodístico. Esta historieta fue publicada por la editorial francesa Delcourt en colaboración con La Revue dessinée en 2019, por bien que un fragmento ya había sido publicado previamente en el n. ${ }^{\circ} 17$ de esta revista en 2017 bajo el título de Algues vertes. Sur la plage empoisonnée. Su propósito es dar a conocer, a través del dibujo, una extensa investigación que incluye una gran cantidad de argumentos y una variedad de fuentes para comprender una situación ambiental crítica, tanto en su actualidad como en su dimensión histórica.

La investigación presente se basa en un riesgo ambiental relacionado con la actividad humana: las llamadas «algas verdes» que proliferan en las playas de Bretaña y Normandía en Francia. El comienzo de este fenómeno data de los años setenta y sus consecuencias ambientales y sanitarias son considerables, dada su alta toxicidad. Las mareas verdes provocan un aumento enorme de la presencia de nitrato en las algas que se depositan en la costa y con las cuales animales y humanos pueden entrar en contacto. Con respecto a las causas, estas mareas son consecuencia de las prácticas de agricultura y ganadería intensiva que comienzan en la postguerra con la modernización del sistema productivo y la introducción del modelo industrial estadounidense en Europa. 


\section{Objetivos}

Entre nuestros propósitos se encuentra el trabajo de discernimiento de la especificidad de la historieta como forma de expresión y de comunicación. Nos orientamos, en particular, hacia su utilidad y eficacia a la hora de transmitir conocimiento relacionado con riesgos y catástrofes naturales. Cabe decir que, si bien nos interesa lo propio de la historieta, no apuntamos a un abordaje esencialista. Trabajamos su especificidad pero no su «naturaleza», entendida como algo intrínseco, inamovible, o, incluso, identitaria. Lo propio de la historieta contemporánea es una transformación constante de sus códigos y procedimientos a través de nuevos géneros, nuevos usos y un común denominador: la narración visual, la secuencia y la articulación texto-imagen en un soporte determinado.

El objetivo de este artículo es proporcionar algunas alineaciones teóricas sobre el modo en que Algues vertes... se apropia de ciertos procedimientos de sentido que podrán, a su vez, extrapolarse a otros objetos de análisis. Pretendemos comprender, pues, el modo en que se problematiza la cuestión del riesgo y de la catástrofe socio-natural en esta historieta, así como identificar los diferentes posicionamientos y puntos de vista confrontados o defendidos, a través de una serie de marcas que nos deja el trazo y el color cuando se encuentran en la secuencia. Este trabajo nos llevará a preconizar ciertas prácticas a la hora de comunicar y transmitir conocimiento a través de la historieta para científicos, instituciones e instancias gubernamentales.

Trabajar sobre el potencial y las posibilidades de este arte nos conduce, incluso, a su legitimación en el campo de la ciencia como un soporte eficiente al transmitir conocimiento.

\section{Elementos metodológicos}

Esta historieta muestra un riesgo natural alevoso. Si bien en este caso es imposible disociarlo de la actividad humana, nos interesa retomar lo que nos explica la antropóloga Sandrine Revet, a saber, la necesidad de relativizar la cuestión del carácter exclusivamente natural de las catástrofes, incluso cuando así lo es en términos estrictos, como puede ser el caso de un seísmo, fruto del movimiento de las placas tectónicas. La actividad humana tiene, en todos los casos, un rol central en el aumento de las condiciones de vulnerabilidad de las sociedades. ${ }^{1}$ En el caso que nos ocupa, se trata de una catástrofe inscrita en el largo plazo, dada la modificación medioambiental que esta opera.

${ }^{1}$ Revet, S. Les coulisses du monde des catastrophes «naturelles». París, Editions de la Maison des Sciences de l'Homme, 2018, p. 4. 
Los recursos a los que Algues vertes... recurre la sitúan en el ámbito de la historieta documental o periodística. Se trata de un género relativamente reciente en el que se genera un híbrido de subgéneros periodísticos, habitualmente influido por los guiones del reportaje documental audiovisual y/o televisivo. ${ }^{2}$ En su definición, el género es un fenómeno intrínsecamente transtextual que se sostiene en la existencia de un contrato implícito con el receptor, lo cual le permite situarse en diferentes lenguajes y soportes mediáticos. Su vida social implica una serie de fenómenos metadiscursivos, como afirma Oscar Steimberg, y se define tanto en el paratexto como en la dimensión temática de los discursos. ${ }^{3}$ Dentro de la masa crítica que contornea los límites del joven género de la historieta periodística, la mayoría de los textos toman a Joe Sacco, periodista y autor de historieta, como referencia obligada, ya que sus obras son fundadoras del género.

Según Séverine Bourdieu, este género se inscribe en la novel categoría de la historieta de lo real, aquella que entra en el territorio de lo factual, recogiendo testimonios, contando vidas reales, etc. Entre las condiciones de posibilidad de la historieta periodística, la más importante es la de la presencia del autor en el campo. Su investigación se basa en recoger testimonios y documentar el tema in situ. El trabajo comparativo con otros objetos periodísticos textuales o audiovisuales también es recurrente en los estudios sobre este género, que defienden una especificidad y posibilidades alternativas de vinculación con el lector. Séverine Bourdieu explica la capacidad de evocación y la posibilidad de restituir una atmósfera propia al dibujo en la historieta, con respecto a la fotografía, más limitada en su presencia fragmentada y escasa dentro del artículo periodístico. $\mathrm{O}$ bien, las dos velocidades en la lectura que el texto y la imagen articulados invocan con respecto a la temporalidad única del relato audiovisual. ${ }^{4} \mathrm{Al}$ gues vertes..., compilación en formato álbum de una serie de trabajos de campo y de entrevistas, cumple con los preceptos mencionados.

En la puesta en imágenes de la historia de las algas verdes y del desastre ambiental que estas representan, se busca explicar el entramado de intereses, la posición oficial, la de la justicia y de los diferentes sectores sociales involucrados. Encontramos una vasta cantidad de actores y un gran trabajo de documentación, con múltiples fuentes explicitadas tanto en el relato como en el paratexto, en pos de justificar y legitimar el punto de vista defendido.

${ }^{2}$ Mitaine, B. (comp.) Scoops en Stock. Journalisme Dessiné, Bd-Reportage Et Dessin De Presse. Chêne-Bourg, Georg Editeur, 2021.

3 Steimberg, O. Semiótica de los medios masivos. El pasaje a los medios de los géneros populares. Buenos Aires, Atuel, 2005, p. 63.

${ }^{4}$ Bourdieu, S. «Le reportage en bande dessinée dans la presse actuelle : un autre regard sur le monde», en COnTEXTES, n. ${ }^{\circ} 11$ (2012), p. 16. Disponible en: https://journals.openedition.org/contextes $/ 5362$ 
En la búsqueda de elementos específicos de la historieta periodística que puedan servir como rejilla de análisis de otras obras pertenecientes al mismo género, es importante partir de una definición amplia de la historieta, que nos permita realizar un desplazamiento constante entre análisis interno y externo, entre lo micro y lo macro. En este sentido, podemos decir que la historieta es un dispositivo, como lo entiende Jacques Aumont, ${ }^{5}$ concretamente, todo lo que rige su relación con el lector: sus propiedades formales, sus cualidades materiales, como el soporte, las técnicas de impresión y de fabricación (en caso de que sea un objeto impreso), sus modos de circulación y de difusión. Se trata de aspectos fundamentales en tanto que trabajamos sobre el tratamiento específico de los riesgos en la historieta periodística. Asimismo, las preguntas sobre quién publica, quién hace la difusión y cuál es el público al que se dirige son insoslayables. En nuestro corpus estos elementos se encuentran en un amplio rango, que va desde la autoedición o fanzine hasta publicaciones mainstream de editoriales de gran envergadura, pasando por la llamada historieta independiente y las publicaciones institucionales. En el caso de Dargaud, se trata de una editorial de cómic de las más importantes de Francia con un amplio catálogo y tiradas importantes cuantitativamente hablando. Esto significa que Algues vertes... puede encontrarse en todas las librerías y, a su vez, el lector tipo conocerá la problemática, dada su presencia previa y su tratamiento en los medios de comunicación en Francia en los últimos cuarenta años.

Con respecto a la instancia autoral y de producción, las preguntas de «¿quién habla?», «¿de qué modo?» y «¿a quién se dirige?» engloban los problemas que abordamos para entender cómo funciona la transmisión de conocimiento y de información, haciendo hincapié en la importancia del posicionamiento de los autores. Podemos decir que el receptor implícito del discurso es alguien potencialmente expuesto al riesgo, es decir, susceptible de sufrirlo en carne propia. Partiendo de ese receptor implícito, Algues vertes... busca concienciar sobre la problemática, denunciar su tratamiento político y corporativo y, sobre todo, alertar a la población en general.

La teoría de la enunciación es una importante herramienta de trabajo en este sentido. Desde el punto de vista de la lingǘstica, el enunciador es una entidad que representa la subjetividad al interior del discurso, por ejemplo, a través de los deícticos de tiempo, lugar y persona. En la historieta, a la enunciación textual, se suma aquella de la secuencia gráfica. Si el rol del enunciador en Algues vertes... es asumido por la autora del guion y periodista que ha realizado la investigación, llevando su voz a las didascalias, la enunciación gráfica, o, como la llama Philippe Marion, ${ }^{6}$ la graphiation, deja sus marcas a través de la imagen, en el trazo y el color, asumidos estos por dibujante y colorista. Estos elementos vienen a situar en este tipo de discurso la mano de los dos

\footnotetext{
5 Aumont, J. L'image. París, Nathan, 1990, p. 101.

${ }^{6}$ Marion, P. Traces en cases: travail graphique, figuration narrative et participation du lecteur. Louvain-la-Neuve, Academia, 1993.
} 
artistas. Federico Reggiani explica que ni en el cine ni en la literatura se encuentra esta diversidad de «focos» que imponen una teoría de la enunciación historietística y que denotan una cierta «incomodidad» en esta dispersión. ${ }^{7}$ Dispersión que lleva, por una parte, al enunciatario a ver, leer y articular el todo en una multiplicidad. Por otra parte, en el caso de la historieta, el conjunto de enunciadores creará sentido orquestando todas estas instancias. A la hora de transmitir una serie de informaciones específicas, como es el objetivo de Algues vertes..., estas dos secuencias amalgamadas permitirán transformar el conocimiento apelando a la opacidad del trazo y a su articulación en la imagen.

\section{Verde que te quiero verde}

Como ya dijimos, Algues vertes... es fruto de una investigación llevada a cabo durante años que apela a una diversidad de fuentes, variados recursos visuales y narrativos para presentar y argumentar. Su recepción es notable, ya que se trata de una obra publicada por una editorial de gran alcance nacional. El tema es conocido por el público que, en muchos casos, ha podido acceder al material con anterioridad en otros formatos, como podcasts, artículos de periódicos, de revistas, entrevistas de radio, reportajes televisivos, en muchos casos, de la misma Inés Léraud. Este volumen nos presenta un contenido completo al mismo tiempo que nos muestra el modo de llevar adelante una investigación periodística. El guion retoma una trama de denuncia y a la vez transmite conocimientos históricos y científicos sobre las causas, los diferentes actores, el modo en que este riesgo ha afectado en mayor o menor medida a las poblaciones y a las víctimas, presentadas con nombre y apellido.

A lo largo y a lo ancho del álbum, accedemos a las voces de todos los actores: campesinos, muertos por intoxicación (entre los que hay humanos y animales), personal hospitalario, periodistas, industriales, políticos, funcionarios, entre otros. Por otro lado, hay una narración estrictamente visual de situaciones que apoyan los argumentos. La posición política es discernible y transmite una gran preocupación frente esta problemática en términos del riesgo que representa y del aumento de la vulnerabilidad de bretones, normandos y visitantes de las regiones ante la negligencia de las autoridades o la defensa de intereses económicos y/o corporativos.

Además de la trama de la denuncia, la historieta sostiene argumentos sobre qué debe cambiar para reducir el riesgo. En una clara apelación a voces de autoridad y de legitimación: toda la información se basa en documentos, detalladamente justificada por fuentes periodísticas y científicas. Dentro del paratexto, el recurso a la nota al pie, los

\footnotetext{
7 RegGiani, F. «"El espesor del signo”: Historietas y enunciación» [Ponencia]. V Jornadas de encuentro interdisciplinario. Las ciencias sociales y humanas en Córdoba, 2007, p. 4. Disponible en: https://historietasargentinas.wordpress.com/2008/04/22/el-espesor-del-signo-historietas-y-enunciacion-federico-reggiani/
} 
anexos y la bibliografía apuntan a una objetividad y un rigor que sitúan el discurso dentro del género periodístico de investigación.

Hay una rica articulación iconotextual en que el dispositivo de la historieta encuentra su razón de ser al dar forma a la investigación. A su vez, esta encuentra el formato ideal en aquella para desplegar su contenido. Numerosas operaciones de sentido se traducen en los «atajos» que permite la imagen múltiple en secuencia: si esta investigación hubiese aparecido en forma textual hubiese seguramente perdido gran parte de su potencial de concienciación.
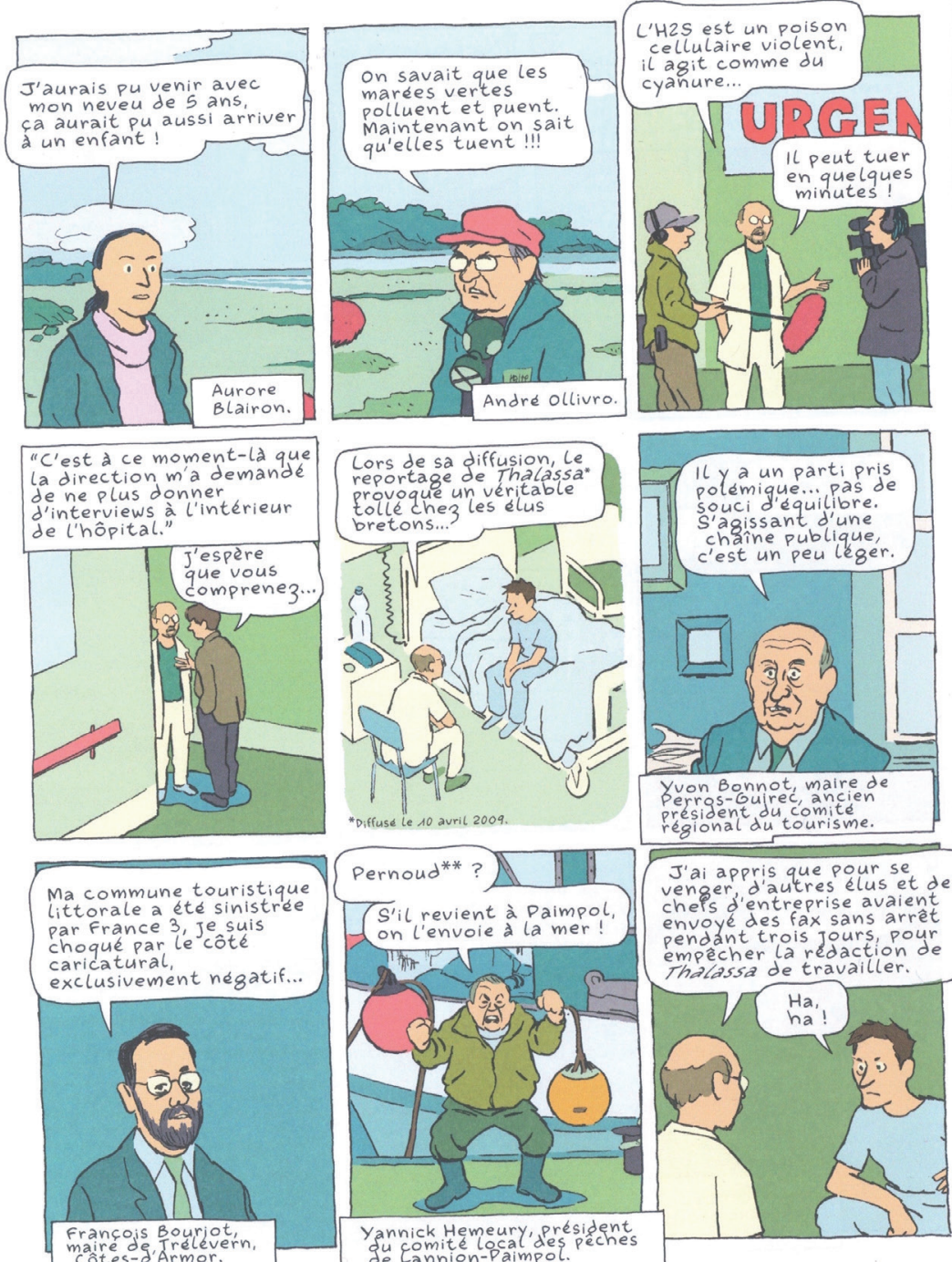

J'ai appris que pour se

chels d'entreprise avaient

envoye des fax sans arret

pendant trois ours, pour

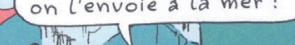

empecher la redaction

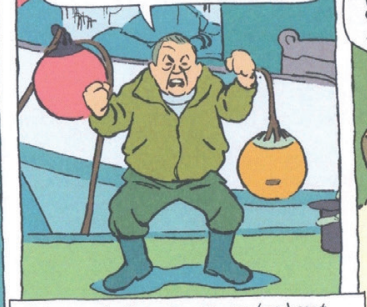

Thalassa de travi

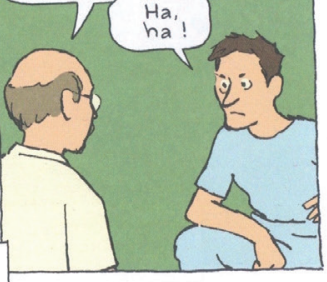

sur cette page, les citations des élus sont issues

du Telégramme (21/04/2009) et de Marianne (25/04/2009).

FIG. 1. Algues vertes: l'histoire interdite

(2019, Delcourt), p. 22. 
La posibilidad de una multiplicidad de voces presentes en un espacio restringido es un recurso de la historieta muy útil en este tipo de trabajos. Podemos hablar de una verdadera polifonía en clave visual: palabras, testimonios, actitudes, opiniones y datos «objetivos» como hechos históricos documentados, cifras y estadísticas, se hallan todos articulados en un espacio coherente. La secuencia permite un efecto de síntesis en el que, por ejemplo, las opiniones de diversos actores, concordantes y/o discordantes (dependiendo de la secuencia en cuestión), aparecen condensadas en una página gracias a la representación de personajes caracterizados a través del dibujo, y al recurso al globo de texto y las didascalias. Veamos, a modo de ejemplo, la secuencia alternada de la página 22 (FIG. 1). Por un lado, seguimos la línea de la historia del médico denunciante Pierre Philippe, que da nombre a uno de los capítulos del álbum. Su conversación con un jinete cuyo caballo muere en contacto con las algas en las playas del departamento francés de Côtes-d'Armor, se alterna con afirmaciones de diversos actores directamente relacionados, como vecinos de la zona, funcionarios y ciudadanos movilizados. En el espacio de una página se nos presenta un panorama de la compleja situación con un poder de síntesis propio de la historieta.

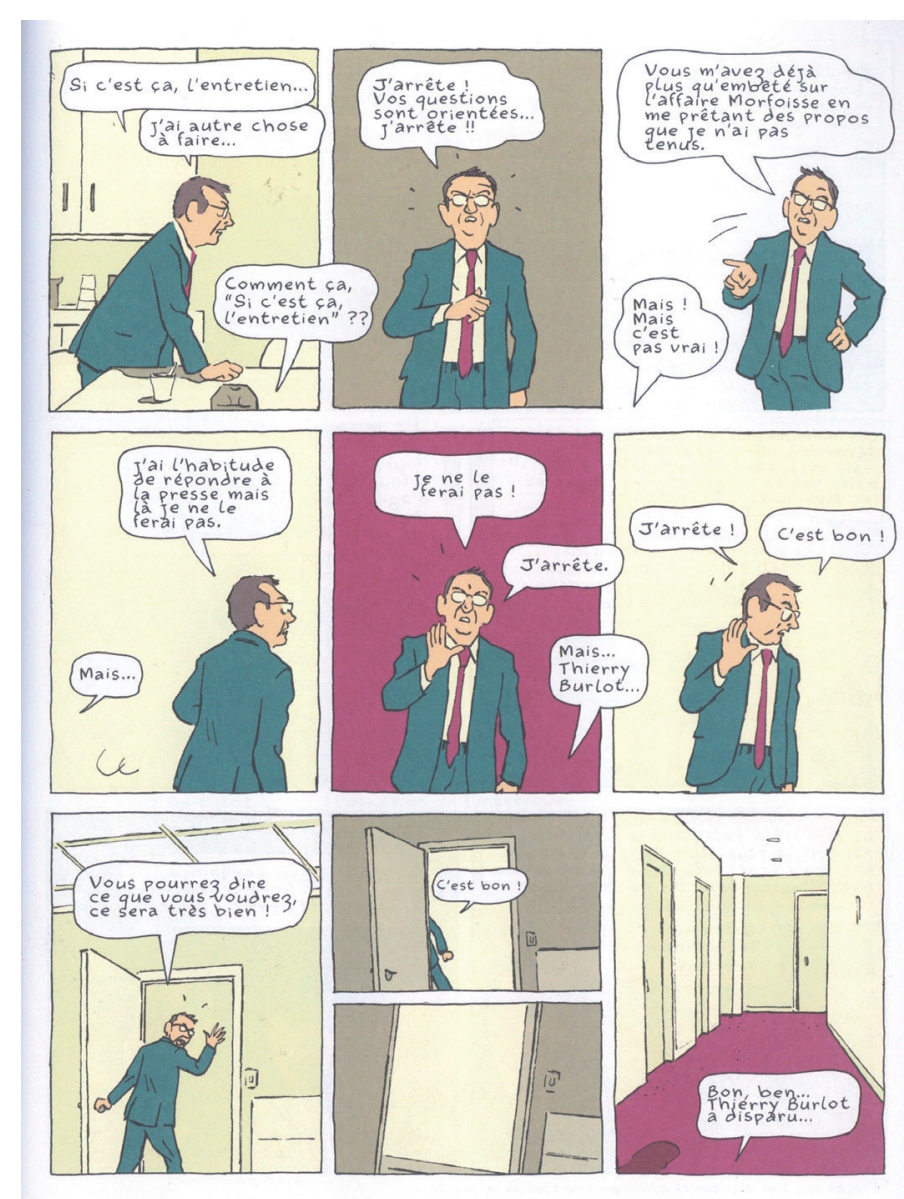

FIG. 2. Algues vertes: l'histoire interdite (2019, Delcourt), p. 87. 
En el mismo sentido, se opera una puesta en secuencia de la comunicación, por ejemplo, de la conversación telefónica o la entrevista, que nos pone, de algún modo, en el lugar de testigos oculares de las conversaciones y que nos permite sacar nuestras propias conclusiones. Concretamente, la secuencia en que un entrevistado molesto y enojado habla directamente al lector, mirando hacia él fuera de página (como un/a actor/actriz mira a la cámara en una película), podemos identificarnos subjetivamente con la periodista, quien está (o mejor dicho, estuvo) objetivamente frente al entrevistado. Esta identificación nos pone «del lado de» la periodista y puede suscitar la misma reacción que ella tuvo ante la actitud de aquel, al momento en que el encuentro representado tuvo lugar en la realidad (FIG. 2). Este recurso busca interpelar y crear una identificación de parte del lector y transmite una subjetividad que pasa por la secuencia visual.

Del mismo modo, algunas secuencias recurren a la narración de hechos a través de las imágenes, en ocasiones mudas, lo que permite contar con énfasis, impactado y sin recurrir a la descripción verbal. Así podemos observarlo en la secuencia de la mujer que en un paseo con sus perros en una playa de Côtes-d'Armor, los pierde de vista para descubrir luego sus cadáveres. Al final de la secuencia, en una página completa, con una pequeña inserción, vemos en primer plano la trompa abierta del can, la lengua saliendo de sus fauces y apoyada sobre las algas, los ojos rojos (FIG. 3). La elección de esta forma de mostrar, en una imagen a página completa y el plano contrapicado con la cabeza del perro en primer plano, apela a un recurso específico de la historieta y entendemos rápidamente la voluntad, una vez más, de interpelar al lector impresionándolo con esta figura cadavérica.

En el estudio de la enunciación gráfica vemos cómo esta se corresponde con un posicionamiento discernible. En una estrategia radical, todo el contenido de la historieta es recreado, con excepciones mínimas, en dibujo: fotos, marcas comerciales, cartas, imágenes de satélite, artículos periodísticos, estadísticas, tapas de revista, mapas, etc. Esta operación unifica visualmente y enfatiza la posición política de los enunciadores, que dejan su marca en los enunciados, cada uno cumpliendo su rol dentro del dispositivo: periodista/guionista, dibujante y colorista. Si los hechos han pasado por el filtro de la periodista y su modo de abordarlos, todo aquello que se representa visualmente ha pasado por el filtro del dibujante y la colorista. En una historieta de este género, el trabajo de documentación periodística es indispensable y si la guionista da pruebas de una ardua labor en este sentido, el dibujante y la colorista están a la altura de las circunstancias. En esta colaboración, los tres autores abrazan el dispositivo plenamente, y hacen uso consciente de las herramientas que este propone en la instancia de producción.

Esta operación de redibujar todo difiere de ejemplos fundadores del género, como lo han sido las obras de Joe Sacco o Didier Lefèvre y Emmanuel Guibert, donde encontramos, en particular, la inserción de fotos en la secuencia dibujada. Esta amplifica- 


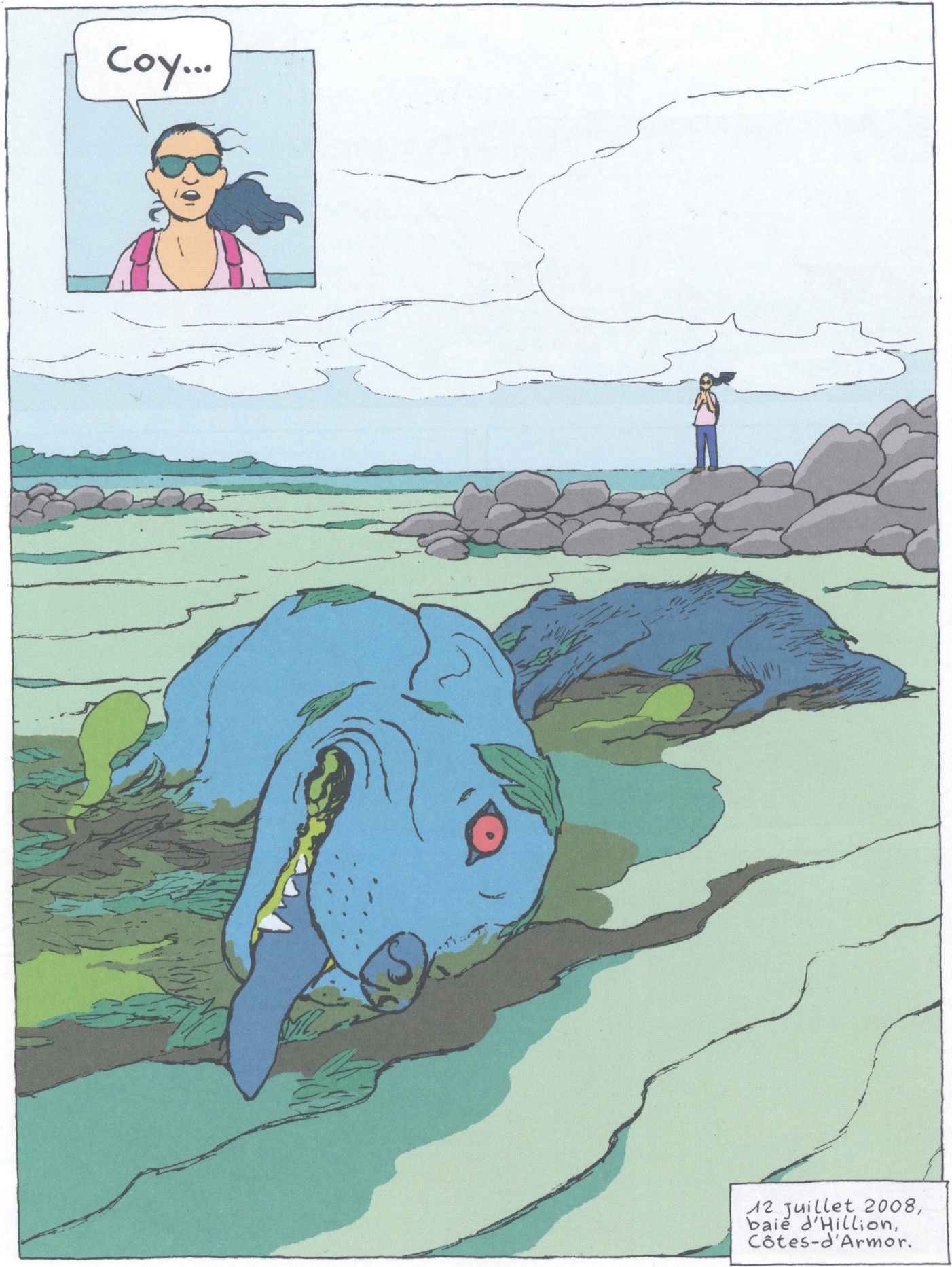

FIG. 3. Algues vertes: l'histoire interdite (2019, Delcourt), p. 18. 
ción del carácter real de lo que se cuenta a través de la fotografía y su búsqueda de objetivar el relato, es relativa en su efecto, dado que la fotografía no es ni más ni menos que una representación al mismo nivel que lo es un dibujo. Este facilita un acercamiento y un nivel de detalle que la fotografía no siempre permite en el trabajo de campo, al correr el riesgo de sobrepasar los límites del respeto o de la identidad de los retratados. ${ }^{8}$

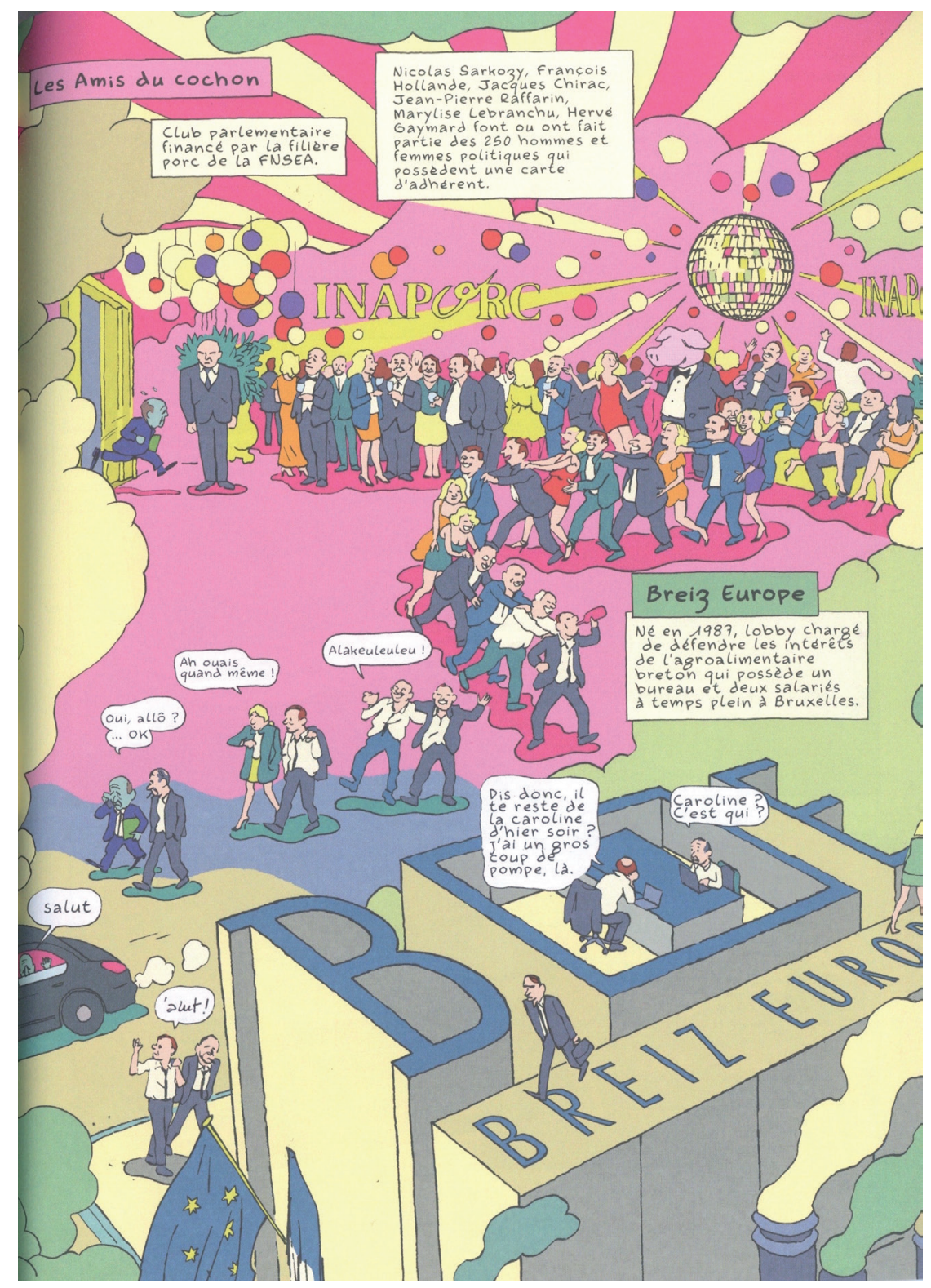

FIG. 4. Algues vertes: l'histoire interdite (2019, Delcourt), p. 95.

\footnotetext{
${ }^{8}$ Bourdieu, S. Op. cit., párrafo 15.
} 
En este sentido, vemos cómo la preponderancia del dibujo y color hacen su trabajo mostrando lo micro en acercamientos radicales, como el del cadáver del perro, y lo macro, en secuencias complejas que condensan eficazmente. Por ejemplo, la secuencia de dos dobles páginas que explican el llamado lobby bretón, aquel que estructura las grandes fortunas de esa región, constituye un panorama muy completo del tema. La narración dibujada se apropia del recurso periodístico de la infografía y la temporaliza. En esta secuencia se explica, en el espacio de cuatro páginas, un entramado complejo de intereses y se presenta a los distintos actores de este lobby el cual, dicho sucintamente, aumenta la vulnerabilidad de la población frente al riesgo de la presencia de algas verdes en las playas, al defender intereses corporativos que perpetúan el sistema de producción actual. No solo accedemos a los aspectos esquemáticos y gráficos de la infografía, sino que también vemos a un personaje que aporta tiempo y espacio al todo: Jean-Yves le Drian, político bretón, que ha asumido cargos en gobierno y como legislador. Este avanza paso a paso en los diferentes espacios que conviven en la imagen como un todo, quedando en evidencia sus vínculos con actores varios, como individuos, grupos económicos, etc. El color hace su trabajo creando recorridos visuales, agrupamientos y caracterizando los diferentes sectores, además de pintar de verde la piel de este personaje real (FIG. 4).

El estilo de dibujo se caracteriza por un trazo que tiende a lo expresivo, sin búsqueda de una representación naturalista, inclinado hacia lo esquemático y caricatural. La línea tiene una presencia pregnante junto al color, que buscan interpelarnos, con un significado propio y autónomo. Evoquemos, para ejemplificar, la historia de Thierry Morfoisse, difunto conductor de los camiones que recolectan las algas en la playa. En esta secuencia el trazo titubeante da cuenta de un malestar físico, y el color se somete a un uso subjetivo. Las pieles verdes toman diferentes significados dependiendo de la secuencia: si en la del lobby caracteriza a aquel que aumenta la vulnerabilidad en la figura del político, aquí representa a la víctima (FIG. 5). El color verde es omnipresente en esta historieta de 160 páginas, en forma de una compleja polifonía verdosa, en diferentes grados de pureza y de saturación, en la que Mathilda crea una fina armonía cromática.

En contraste con una fuerte intención de objetividad, la representación de lo subjetivo está muy presente y apoya los propósitos de la historieta: junto a datos y hechos conviven puntos de vista, impresiones, vivencias y sensaciones. Esta articulación juega un rol de intensificación del mensaje a través del énfasis. El lector accede, a la vez, a datos y a opiniones como una proyección de la vida misma, recurso habitual en el reportaje periodístico televisivo.

En última instancia de este análisis, veamos la figuración de personajes y algunos problemas que se suscitan en la representación. El hecho de que esta historieta sea documental hace que todos ellos existan en la realidad y sean más o menos mediatizados. Su tratamiento genera algunas dudas en términos de coherencia a la hora de 

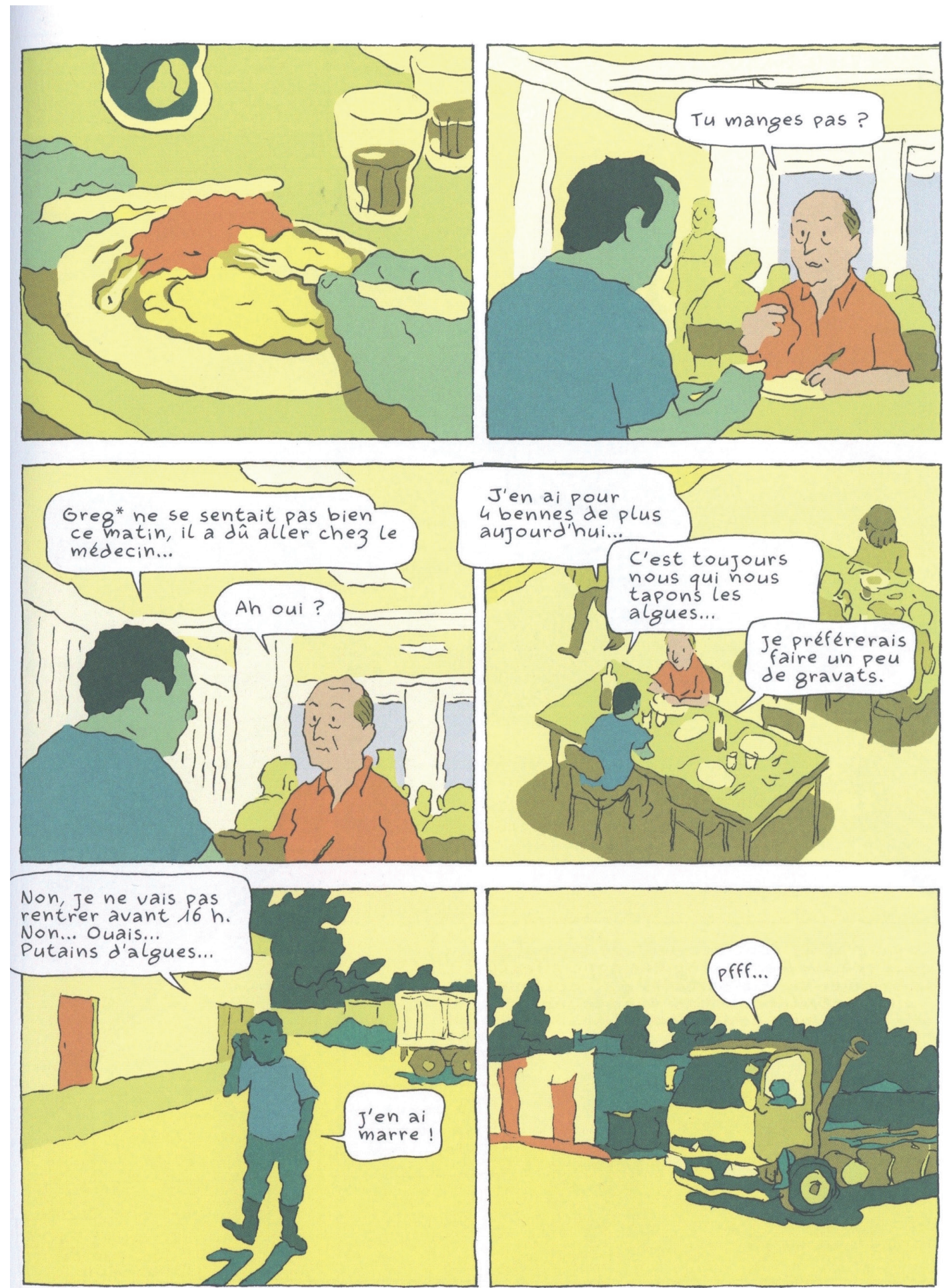

* Le prénom a été modifié.

FIG. 5. Algues vertes: l'histoire interdite (2019, Delcourt), p. 35. 
representarlos, dado el amplio rango en los grados de caricaturización. Por ejemplo, cuando vemos a Charles de Gaulle en una representación muy caricaturesca, exagerando rasgos como las orejas y la nariz, nos sorprende encontrar, en otras secuencias, representaciones que podrían provenir de una búsqueda de retrato naturalista, basado en fotografías, sin exagerar rasgos y buscando la complejidad de expresiones faciales. Estas representaciones antagónicas pueden hacer mella en la legibilidad y poner en peligro la efectividad del mensaje que se busca transmitir (FIG. 6). Puede, por ejemplo, confundirse con una animosidad hacia ciertas personas, lo cual alejaría el mensaje del propósito de mantenerse en una cierta línea de objetividad y de rigor en la información. En efecto, la representación de personajes aparece como arbitraria. Los actores que intervienen están más o menos caracterizados pero la diferencia entre unos y otros es demasiado grande. ¿A qué responde esta falta de homogeneidad? ¿Existe un patrón? Si de hecho lo hubiera, al requerir demasiado esfuerzo el poder descifrarlo, no estaría funcionando correctamente en la instancia de recepción, lo cual crea un desfase entre las intenciones de los autores y la percepción de los lectores.

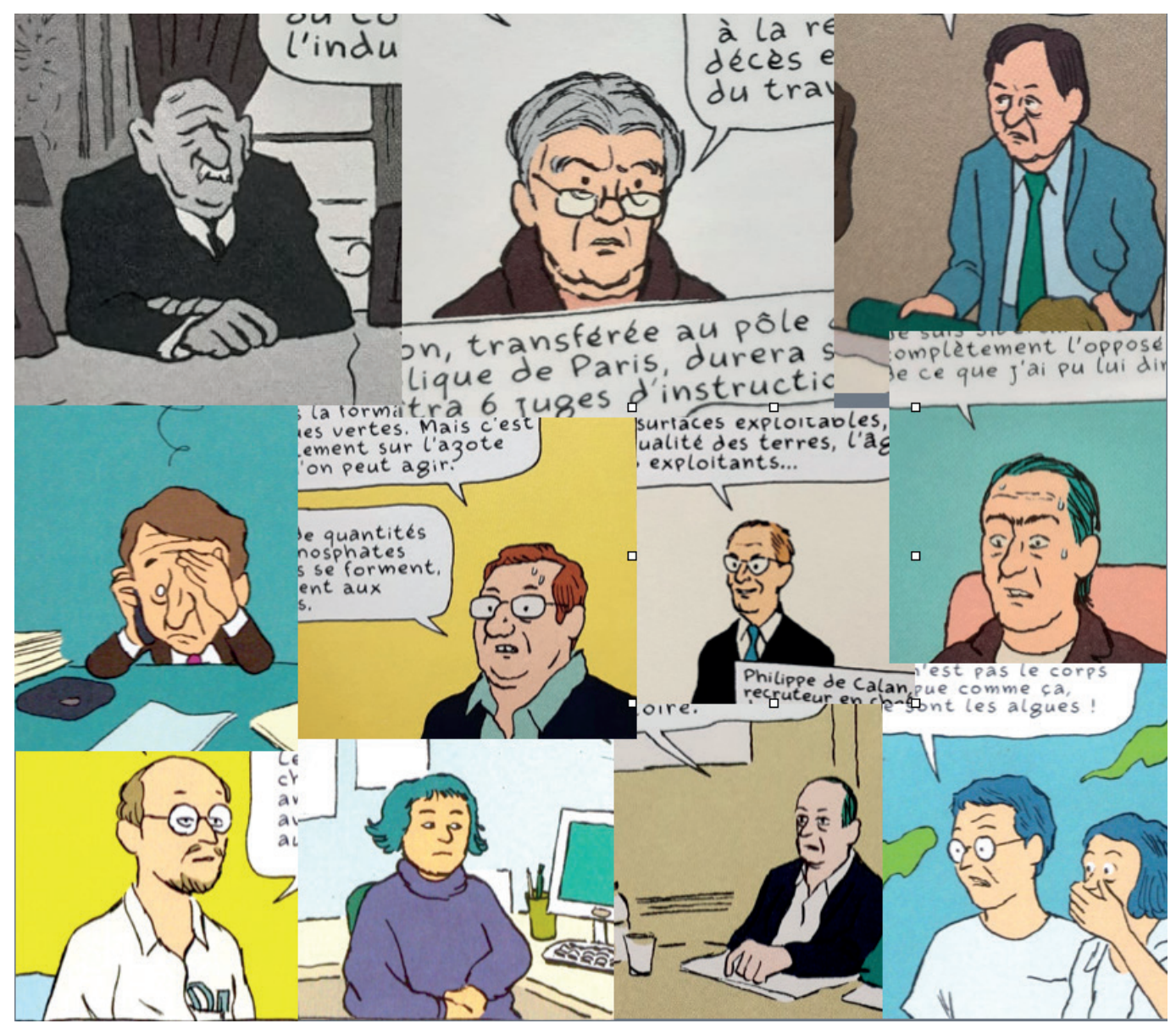

FIG. 6. Algues vertes: l'histoire interdite

(2019, Delcourt), Extractos. 
Operaciones variadas complementan las que hemos referido en este texto bajo la forma de algunas pistas de análisis historietístico. Hemos tratado, aquí, de mostrar estrategias más o menos logradas en términos de transmitir conocimiento y persuadir, sin obviar que muchos otros ejemplos podrían complementar este estudio.

\section{Conclusiones}

La historieta es una forma de arte y una herramienta muy útil, a condición de poder explotar el máximo de su potencial. En el caso de Algues vertes..., hay un uso consciente de los recursos propios de este dispositivo que le permiten transmitir conocimiento y presentar una posición determinada frente a los hechos. En este artículo buscamos exponer una serie de reflexiones a partir del análisis de secuencias concretas, así como de ciertos aspectos generales, haciendo hincapié en el modo de comunicar.

Mientras el trazo, el color y la articulación de la secuencia facilitan la comprensión de los fenómenos evocados y es exitosa en la mayor parte de los casos, un conocimiento profundo del dispositivo nos permite detectar ciertos elementos que pueden interferir en la coherencia del relato. La representación de personajes es problemática ante la ausencia de un patrón: el amplio rango entre retrato y caricatura que conviven sin criterio parece difícil de justificar. El tono prudente y respetuoso de esta historieta, que trata de un azote ambiental real, entra en colisión con esta incoherencia. Sin embargo, podemos decir que Algues vertes... permite una transmisión de contenidos y que busca, a la vez, generar una mirada crítica e informada. Entender cómo funcionan este tipo de historietas en todas las dimensiones del dispositivo nos permite avanzar en nuestro estudio y en la búsqueda concreta a la hora de crear instancias de transmisión en la reducción de riesgos.

La historieta se ocupa muchas veces de contar la historia, de representar, en definitiva, mundos diversos. En este sentido, concluimos que su uso consciente puede, también, transformar la realidad. 


\section{Bibliografía}

Aumont, J. L’image. París, Nathan, 1990.

Bourdieu, S. «Le reportage en bande dessinée dans la presse actuelle: un autre regard sur le monde», en COnTEXTES, n. ${ }^{\circ} 11$ (2012). Disponible en: https:// journals.openedition.org/contextes/5362

Marion, P. Traces en cases: travail graphique, fguration narrative et participation du lecteur. Louvain-la-Neuve, Academia, 1993.

Mitaine, B. (comp.) Scoops en Stock. Journalisme Dessiné, Bd-Reportage Et Dessin De Presse. Chêne-Bourg, Georg Editeur, 2021.

RegGiani, F. «"El espesor del signo”: Historietas y enunciación» [Ponencia]. V Jornadas de encuentro interdisciplinario. Las ciencias sociales y humanas en Córdoba, 2007. Disponible en: https://historietasargentinas.wordpress.com/2008/04/22/ el-espesor-del-signo-historietas-y-enunciacion-federico-reggiani/

Revet, S. Les coulisses du monde des catastrophes «naturelles». París, Editions de la Maison des Sciences de l'Homme, 2018.

Steimberg, O. Semiótica de los medios masivos. El pasaje a los medios de los géneros populares. Buenos Aires, Atuel, 2005. 